\section{Ethics of genomic patenting}

SIR - George Poste, in setting out SmithKline Beecham's "case for genomic patenting" (Nature 378, 534-536; 1995), has too readily implied that it is accepted by the Nuffield Council on Bioethics. In its report, Human Tissue: Ethical and Legal Issues, the council made three relevant points (pp 135-136):

"We recognise that inventions derived from human tissue are open to patenting. Over two hundred patent applications have been published where the criteria for patentability have been met. We accept this position as a matter of fact.

"There is at present a major controversy about patenting in the area of human genes. The law, as it stands, discriminates between discoveries and inventions. Fundamental to the application of the notion of invention in this area is that some technical intervention should have taken place that justifies the granting of an intellectual property right. We note that questions of fact arise in each case on whether patent applications meet the existing legal criteria.

"We attach great importance to the fuller consideration and review of the process by which ethical issues are taken account of in relation to the question of patenting inventions derived from human tissue. We recommend that the Government joins with other member states of the European Patent Convention (EPC) in adopting a protocol to the EPC which would set out in some detail the criteria to be used by national courts when applying the immorality exclusion to patents in the area of human and animal tissue."

The council's 'endorsement' of patenting was directed primarily at 'inventions derived from human tissue', and in particular at applications to patent cell-lines. On the patenting of human genes, the council reserved its verdict, while stressing the distinction drawn in law between discoveries and inventions, which causes difficulties for patent offices in this area.

On my personal reading of Poste's discussion of SmithKline Beecham's policy, and Merck's policy on genomic patents, the latter's ethical position has much to be said for it, not least that it maintains the distinction between discovery and invention.

\section{David Shapiro}

Nuffield Council on Bioethics,

Nuffield Foundation,

28 Bedford Square,

London WCIB 3EG, UK

\section{Austrian science}

SIR - Research in biochemical sciences in Austria was recently evaluated by a dozen colleagues from different countries selected by the European Molecular Biology Organisation (EMBO) (see Nature 377, $468 ; 1995)$. These experts took on a formidable task and produced an objective and balanced review.

But the Nature article does not truly reflect the tenor of the experts' report. The introduction to the report says that "[i]n several areas of biomolecular research very good and excellent work is being carried out", yet "the greater part of Austrian biomolecular research cannot be classified as being internationally leading or competitive" and "a relatively large number of groups have to be classified as poor in their scientific output".

Unfortunately, the Nature article dwells mainly on the most negative statements of the introduction and fails to consider the analysis of the individual research groups which reveals a more positive situation. Thus, of the 79 groups evaluated (from 8 universities and a few other institutions), 54 were rated as good or very good, the rest as average or poor. We fully agree that each group in the lower two categories is one too many, but we believe that biomedical research in Austria is not at the level you depict. Moreover, after the evaluation, Professor G. Czapski (Jerusalem) carried out a detailed statistical analysis of Austrian publications in the biochemical sciences for the Austrian Biochemical Society. In this analysis Austria ranked fifth and seventh (among 58 countries) with respect to the proportion of top papers in biochemistry/biology and molecular biology/genetics respectively.

A fair and objective comparison of biochemical research in Austria and its European neighbours is currently not possible. Only when other countries have come under the scrutiny of similar impartial committees can a valid comparison be made. The Austrian Biochemical Society agrees with a large part of the assessment of individual groups in the report by the EMBO panel and acknowledges that the number of internationally recognized scientists is too small and the average scientific productivity too low. We face the challenge to increase both and hope that the report will lead to changes in employment and funding policies in Austria that will reward scientific productivity.

\section{Hermann Esterbauer}

Institute of Biochemistry,

University of Graz,

Schubertstrasse 1,

A-8010 Graz, Austria

Ernst Kuechler

Vienna Biocenter,

University of Vienna,

Dr Bohrgasse 9,

A-1030 Vienna, Austria

\section{Gunther Kreil}

Institute of Molecular Biology,

Austrian Academy of Sciences,

Billrothstrasse 11,

A-5020 Salzburg, Austria

Fritz Paltauf

Institute for Biochemistry,

Technical University Graz,

Petersgasse 12,

A-8010 Graz, Austria

\section{Foreign workers in Europe}

SIR - As an American postdoc for the past two years in both France and Germany, I feel compelled to comment on both your figures and their interpretation in your leading article about Germany (Nature 378, $755 ; 1995)$. There appears to be a disparity between the number of European Commission (EC) Human Capital and Mobility (HCM) fellowships going to Britain, France and Germany. However, of the three, only Germany has significant internal funding sources for foreign postdocs. By contrast, foreigners in France and the United Kingdom are almost completely dependent on the EC Fellowship programme. If one were to study all postdocs in Europe (not just those sponsored by the EC), I am certain Germany would be better represented.

As for the language and bureaucratic barriers to foreign scientists in Germany, my experience after a year each in Germany and France is exactly opposite to what you report. During the time I was employed by the French CNRS, a law (deplored in these pages) required me to conduct all my daily scientific work in French. Few of my colleagues, though able, were willing to speak English at work anyway. It was nearly impossible to conduct any science there without a working command of French. The CNRS paid for French lessons for me, and I enjoyed learning, but it took massive amounts of research time away to do so. Here I need speak almost no German on the job at all, even though my German is already nearly perfect. However one may feel about that, language is not a greater barrier to foreign scientists here than in France. My residence permit took an hour to get in Germany; in France it took 6 months, several lost work days, and repeated humiliation by bureaucrats in the Hotel de Police and the Mairie. My experience was not unique, the price I suppose for an otherwise happy and productive year in France.

And I experienced much more Ausländerfeindlichkeit in France than here, often expressed openly by government officials in the course of their duties, and without much reflection. Such a thing is impossible here, now, without a huge public uproar. If the point of your leading article was that foreign stereotypes about Germany do not square with reality, you are clearly right. You imply that Germany is in fact less welcoming to foreign scientists than other European countries: there you are wrong, in my view.

\section{Jonathan E. Snow}

Max-Planck Institut für Chemie,

Abt Geochemie,

Postfach 3060,

D-55020 Mainz,

Germany 